Article

\title{
The Admiral Nurse Role in UK Hospice Care: A Satisfaction Survey Evaluation to Explore Carer Experiences
}

\author{
Sue Read ${ }^{1, *}$, Caroline Reeves ${ }^{1}$, Julie Green ${ }^{2}$, Karen Harrison Dening ${ }^{2}$ \\ 1 School of Nursing and Midwifery, Keele University, Staffordshire ST4 6QG, UK \\ 2 Dementia UK, 7th Floor, One Aldgate, London EC3N 1RE, UK \\ * Correspondence: Sue Read, Email: s.c.read@keele.ac.uk.
}

\begin{abstract}
Dementia is an increasingly common condition among the older population. It is characterised by multiple cognitive deficits leading to decline from premorbid level of functioning. In 2015 it was estimated that there were over 850,000 people in the United Kingdom (UK) living with dementia and approximately 7,000,000 family carers of people with dementia in the UK. Carers are finding themselves providing increasing amounts of care and support for their loved ones, often independently. Whilst carers find that providing support can have its rewards, it is more the case that it can be challenging and have an impact on their psychological and physical health, and can change existing relationships. It can be extremely exhausting and isolating and, additionally, be at great personal financial cost to them.
\end{abstract}

The aim of this paper is to introduce an Admiral Nurse two year project established in a hospice in the West Midlands, supported by Dementia UK, a national charity often seen as the voice of dementia in the UK. It briefly describes the clinical context of this service and how an independent evaluation was commissioned with a local University to identify the impact of this service from a clinical, operational and strategic perspective. As part of the evaluation strategy, a survey of carers who had used the Admiral Nurse service was conducted. This paper will focus upon the survey and its outcomes and will consider: how these help professionals to appreciate the complex support needs of people with dementia; inform the developing Admiral Nurse's role; and help professionals to think about future hospice services and their client populations. The paper will end with conclusions and recommendations relating to the lived experiences of family carers and the Admiral Nurse's role and its position in future care and support of patients with dementia.

Copyright (c) 2019 by the author(s). Licensee Hapres, KEYWORDS: dementia; family carers; satisfaction survey; evaluation London, United Kingdom. This is an open access article distributed under the terms and conditions of Creative Commons Attribution 4.0 International License. 


\section{INTRODUCTION}

\section{Dementia}

Dementia is an increasingly common condition among the older population. It is characterised by multiple cognitive deficits leading to decline from premorbid level of functioning. The ICD-10 Classification of Mental and Behavioural Disorders [1] defines dementia as a collection of symptoms which arise as a result of brain disease or damage and is usually chronic or progressive in nature. Several cognitive activities, including memory, thinking, comprehension, calculation, learning, language and judgement may be affected. In addition there may be changes in emotional control, social behaviour or motivation. Alzheimer's disease (AD), vascular dementia (VaD) and dementia with Lewy bodies (DLB) remain the main underlying causes [2].

In 2015 it was estimated that there were over 850,000 people in the United Kingdom (UK) living with dementia; and approximately 7,000,000 family carers of people with dementia in the UK [3]. These carers are finding themselves providing increasing amounts of care and support for their loved ones [4,5], often independently. Such family carers find that this support can often be both challenging and yet rewarding; can have an impact on their long term psychological and physical health; can change existing relationships [3]; can be extremely exhausting and isolating; and, in addition, be at great personal financial cost to them. Whilst the numbers of people diagnosed with dementia is increasing worldwide, the ebb and flow of dementia care and support provides an inadequate and variable consistency across this increasing population.

\section{Burden of Caring}

Family carers of people with dementia provide most of the care and support in the UK. This is often associated with high personal emotional and financial cost. Estimates made by the Dementia UK report [6] indicated that approximately $50 \%$ of the financial costs of dementia to society as a whole was met by family carers [6]. In 2014 the Alzheimer's Society reported that two-thirds (£17.4 billion) of the overall cost of dementia care was being met by people with dementia and their families, either as unpaid care (£11.6 billion) or through paying for social care. In a review for the House of Commons [7]) further highlighted the economic impact of working age carers who had to leave work to care for a family member with dementia. Parkin \& Baker predicted that by 2030, the cost of the skills and experience lost from the workforce due to dementia will rise from the current $£ 628$ million to $£ 1.16$ billion [7]. This work can have negative consequences for family carers' health and wellbeing. Accessing timely and relevant support and services is important to carers, however the experience is often reported as difficult [8], especially when faced with the need for palliative and end-of-life care. 
It seems that dementia support potentially comprises four distinct (but potentially overlapping) categories: those who have been dementia care givers; those who are going to be dementia care givers; those who are receiving dementia care; those who will need dementia care. Therefore the impact on those supporting people with dementia is potentially vast; it can be demanding, challenging and tiring for relatives.

\section{Palliative and End-of-Life Care in Dementia}

One in three people will die with or from dementia. Dementia is a lifelimiting condition with an average life expectancy of 4.5 years after diagnosis [9]. Nevertheless, the number of people accessing specialist palliative care services remains low, with only $1 \%$ of people with dementia dying in a hospice and less than $10 \%$ dying in their own home [10].

Palliative care is defined as the active, total care of patients whose disease is not responsive to curative treatment. Control of pain, of other symptoms, and of psychological, social and spiritual problems is paramount [11]. It is a "whole person" approach, with an emphasis also to the needs of those who matter to the person with dementia; their families, carers and friends. Although dementia has been identified as the leading cause of death in England [12], there is still widespread evidence that people with dementia have inequitable access to good palliative and endof-life [10,13] and hospice care [14].

\section{Hospice Enabled Dementia Care}

Dementia care is an increasingly important strategic consideration for hospices in the UK. In 2014, Hospice UK reported on the role hospice could play in supporting people with dementia to live and die as well as possible [16]. The report outlined how hospices can be best supported to include dementia in their everyday practice and suggested an initial audit and review of current practice and service model. The Douglas Macmillan Hospice, Stoke on Trent, Staffordshire, was one of the first hospice in the UK to appoint an Admiral Nurse (see Figure 1). The hospice strategy and vision identified the need to develop services to embrace people affected by dementia and decided to implement dementia case management by recruiting an Admiral Nurse. As part of the formal, independent evaluation of the Douglas Macmillan Hospice Admiral Nurse two year funded project conducted independently by Keele University (2017-2019), a family carer survey was conducted in the summer of 2018. 
- Admiral Nurses focus on the needs of the whole family affected by dementia, including psychological support to help the person with dementia and family carers to understand and deal with their thoughts, feelings and behaviour, and to adapt to the changing situation.

- Admiral Nurses uses a range of evidence-based interventions that help people live as well as possible with the condition and develop skills to improve communication and maintain their relationships.

- Admiral Nurses work with families throughout the illness but particularly at points of difficulty, including diagnosis, as the condition progresses, or when tough decisions need to be made, such as moving a family member into residential care. Anticipated problems might be: miss or delayed diagnosis; lack of information and which may increase risk or inappropriate management; crises; poor psychological adjustment to the diagnosis; reduced coping capacity and the ability to forward plan.

- Admiral Nurses help families cope with feelings of loss and bereavement as the condition progresses. Families affected by dementia require support throughout the illness of dementia and into bereavement. For family carers, the more social support that is received during the years of caregiving, the easier it is to adjust and adapt post bereavement.

- Admiral Nurses provide case management to ensure all appropriate services and care are available to a family, including liaison with other professionals on behalf of the family.

Figure 1. The Admiral Nursing approach [15,17].

\section{EVALUATION METHODS}

Evaluation can be described as a as a form of "disciplined enquiry" [18] that applies scientific procedures to the collection and analysis of information about the content, process, structures and outcomes of projects [19]. Whilst evaluation can be applied in a number of differing contexts, and for a number of differing reasons, in this context it was used to determine the merits or value of the Admiral Nurse to support people with dementia and their families, as part of hospice development.

The evaluation used a number of methods to determine the merits of the Admiral Nurse service, including focus groups, case studies and survey methods, however this particular article will focus only on the survey that was conducted. Questionnaires and surveys are recognised as cost effective, useful tools for accessing a range of participants to generate invaluable sources of data about attitudes, values, experiences and behaviours in the social sciences [20]. This particular survey used a mixed method approach consisting of 18 questions that elicited feedback using both a 5-point Likert scale and a box for free text comments. The survey tool used was an established, well tested instrument with family carers of people with dementia [21,22], used with kind permission from Dementia UK. The survey aimed to capture the carer experiences of those accessing the Admiral Nurse service in the Stoke on Trent and Staffordshire area, UK. and was distributed by post to families who had been supported by the Admiral Nurse during the first year of the project. 


\section{Ethical Considerations}

This project was an evaluation of service development and therefore did not require National Health Services (NHS) ethical approval. An action research framework was used to underpin the exploration purely because it afforded us the opportunity to routinely engage fully with a range of clinicians and others, using a cyclical approach to inform change. Although not perceived as requiring ethical approval, principles of good ethical practice were followed throughout by fully informing anyone participating about the project and by obtaining consent from all participants.

\section{RESULTS}

"The Admiral Nurse is an exemplary nurse providing clinical, practical and emotional support...I don't think I could manage without her..."

-Survey Respondent: Daughter carer of person with dementia

Forty five family carers were surveyed which yielded a $56 \%$ response ( $n=26)$; the demographics of the 26 respondents can be found in Table 1 . The outcomes of this survey are presented to provide a flavour of the experiences of dementia care and support from a personal care perspective in one hospice in the West Midlands area of the UK.

Of the 26 respondents who completed this survey questionnaire, 22 (85\%) were female; all identified themselves as White British. Nineteen (73\%) of the respondents were aged 65 or over with one person 85 years or over (see Table 1 ). Twenty carers (76\%) provided upwards of 70 hours per week on their caring role (see Figure 2).

Table 1. Demographics of participants $(n=26)$.

(A) by Gender.

\begin{tabular}{c|c|c}
\hline White British & Male & Female \\
\hline 26 & 4 & 22 \\
\hline
\end{tabular}

(B) by Age.

\begin{tabular}{c|c|c|c|c|c}
\hline 18-34 years & 35-54 years & 55-64 years & 65-74 years & 75-84 years & 85 years plus \\
\hline 0 & 2 & 5 & 10 & 8 & 1 \\
\hline
\end{tabular}

Regarding the specific role of the Admiral Nurse 54\% $(n=14)$ of respondents saw an Admiral Nurse between 5 and 10 times, with face to face being the most popular mode of support by 21 participants ( $81 \%$ ), and this was judged to be about right for those involved (96\%). Accessing an Admiral Nurse was deemed easy by $88 \%(n=26)$ of respondents, using the established referral pathway developed.

Supportive interventions were also clearly identified (Figure 3). Overall the Admiral Nurse was deemed by respondents to provide support that 
was person centred, with the four most helpful skill areas identified as knowledge and information; holistic assessment; supporting carers with decision making, and helping to anticipate prevent and avert crisis. Explicit interventions or skills of the Admiral Nurse included spending time and not rushing; listening; responding to questions; and showing compassion, respect and understanding (see Figure 3).

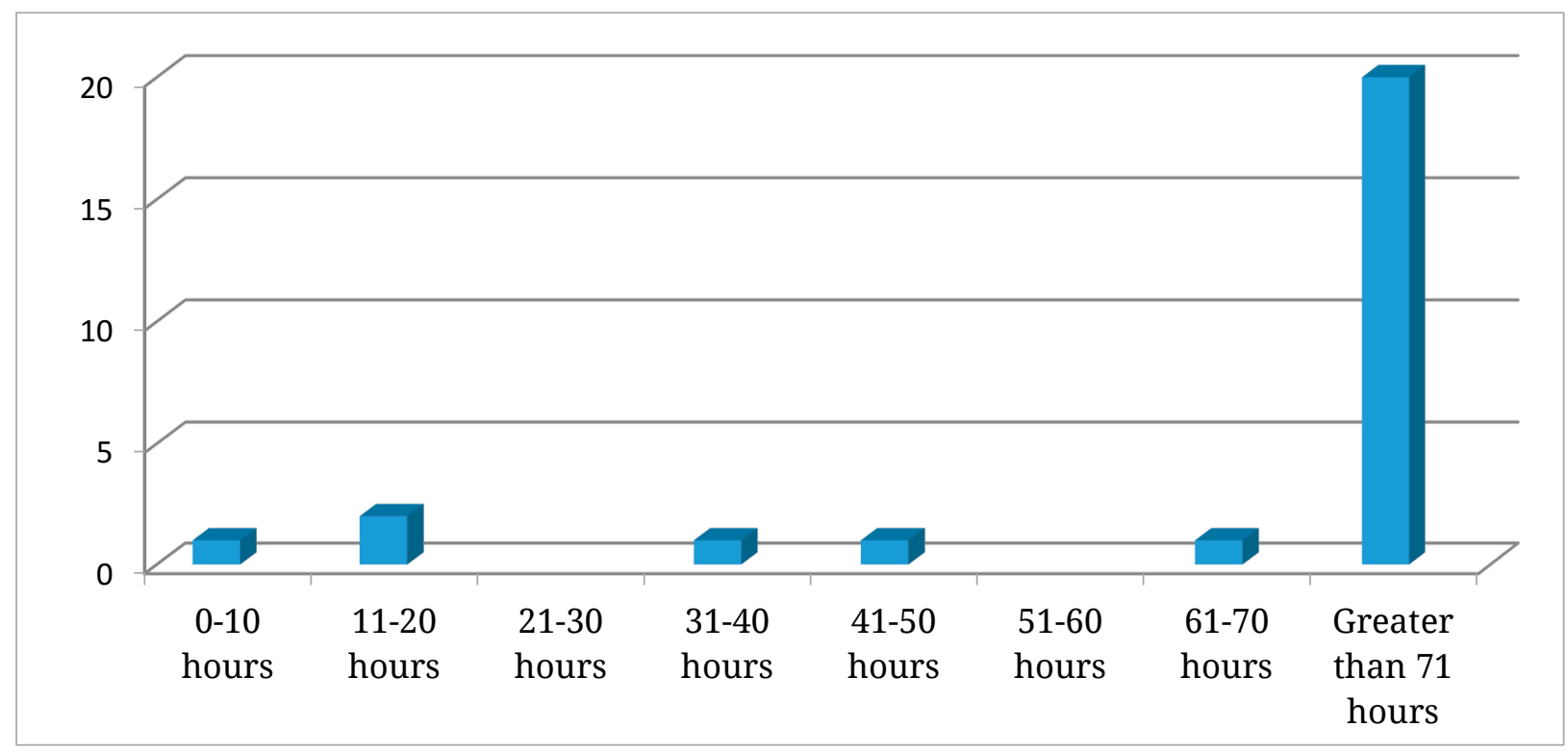

Figure 2. Hours spent by carers supporting a family member with dementia.

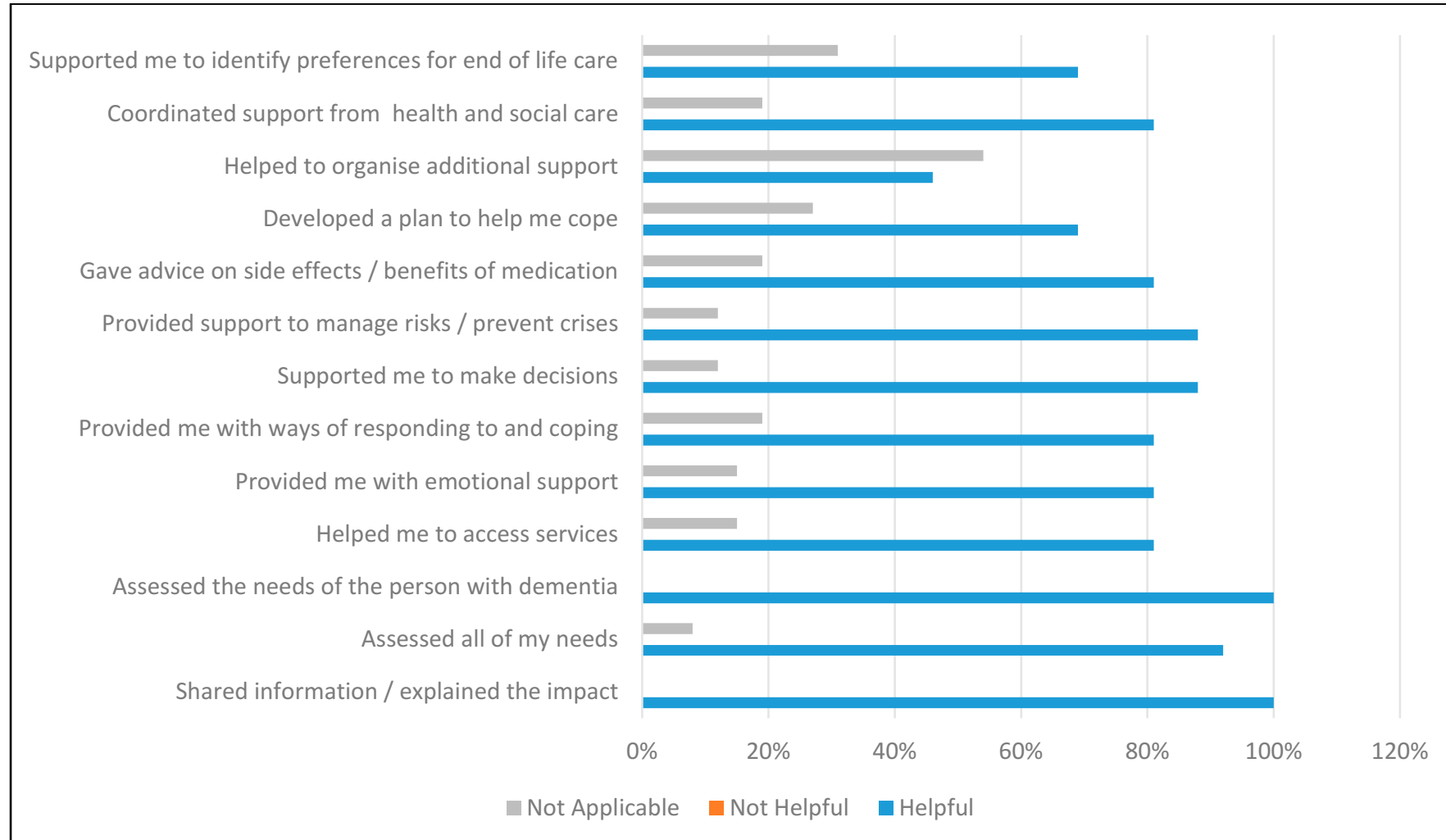

Figure 3. Explicit skills of the Admiral Nurse. 
The nature (see Figure 4) and impact of the Admiral Nurse was expectedly variable, since individual needs vary so much as do expectations, but the biggest impact was around the carers' ability to make decisions; to take better care of their loved ones; increased confidence in coping; and self-care (looking after themselves) (see Figure 5).

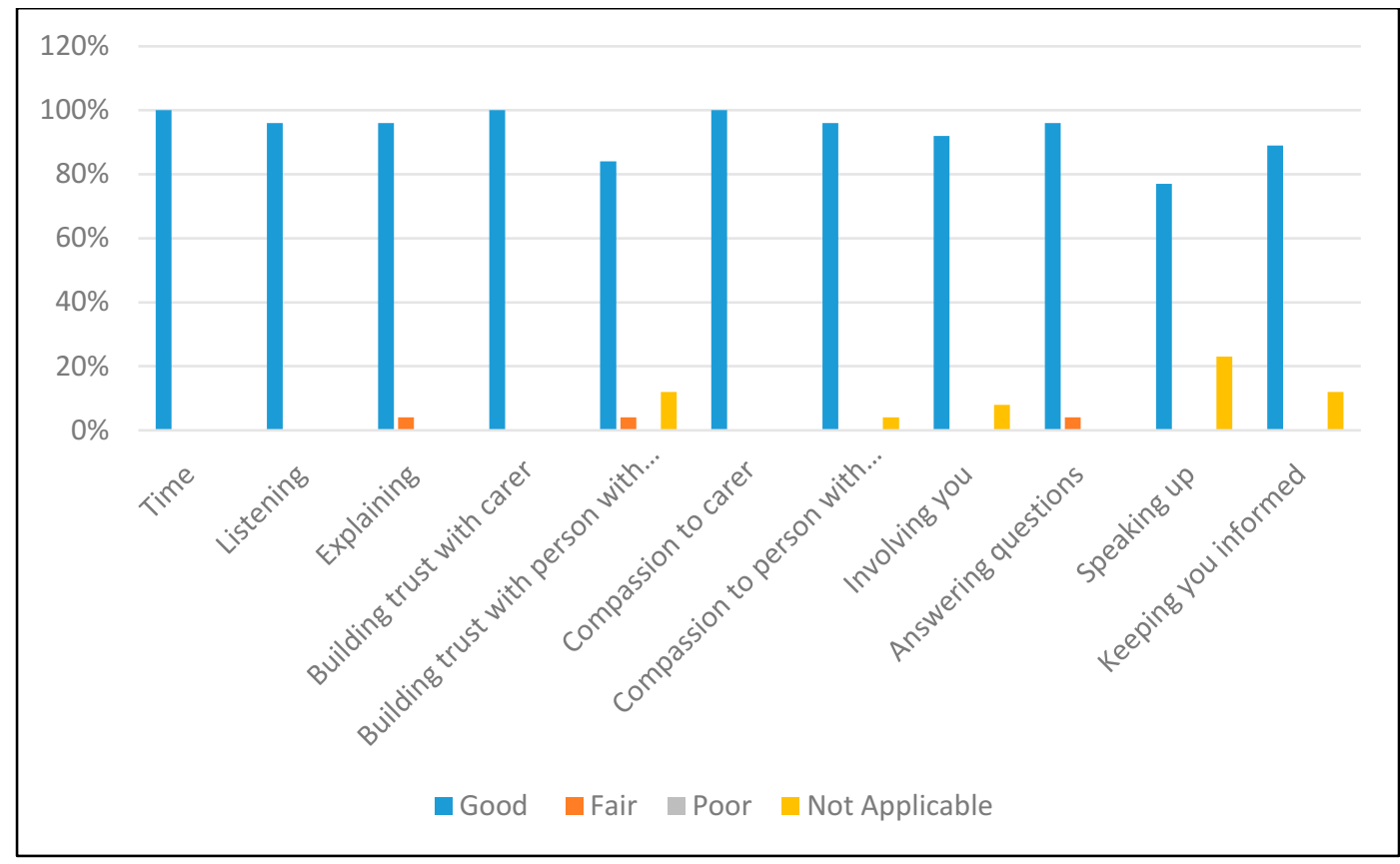

Figure 4. The nature of support provided by the Admiral Nurse.

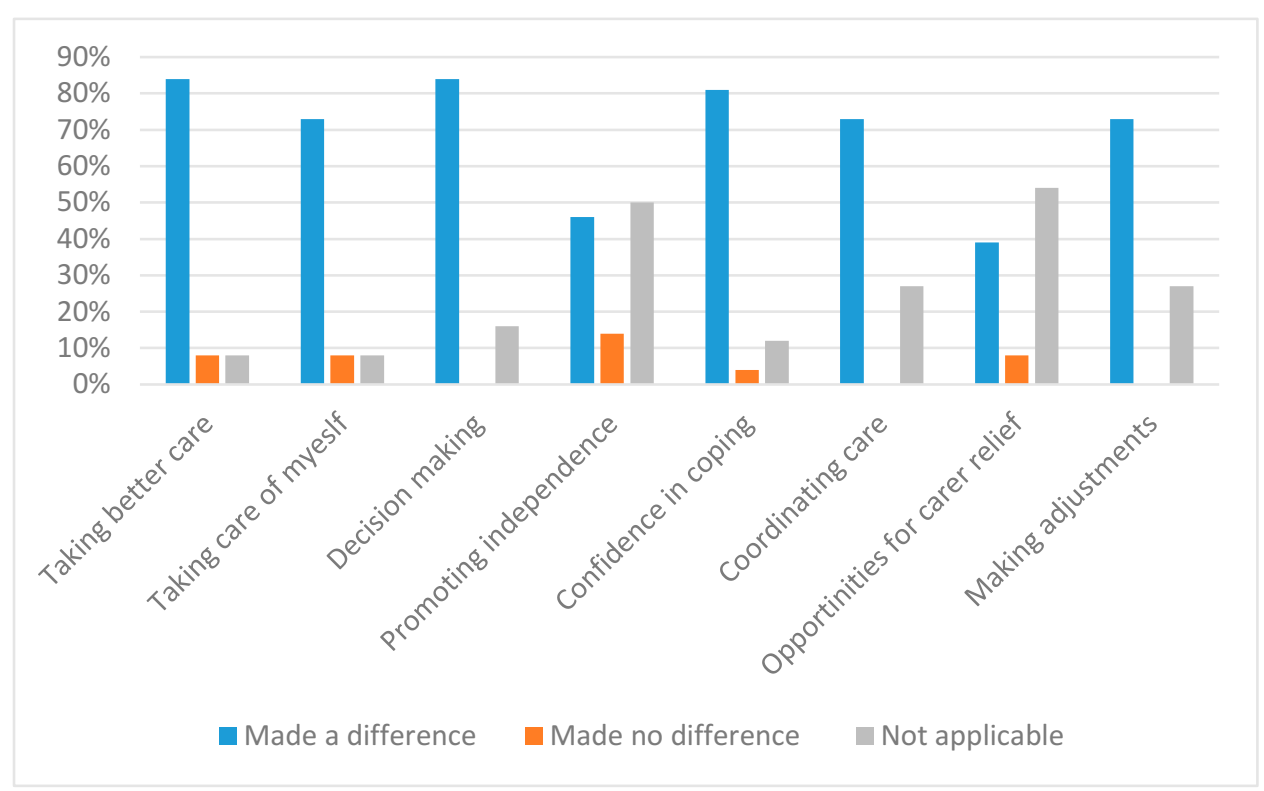

Figure 5. Impact of an Admiral Nurse.

As a new specialist role, distinguishing this role from existing ones is important to avoid duplication. Differentiating between the role of the Admiral Nurse and other healthcare professionals firmly established the importance of specialist knowledge and information; the personal approach adopted; and the recognition that time (that important 
commodity) was available for the family as well as the person with dementia (see Figure 6). Respondents could tick more than one box in this section.

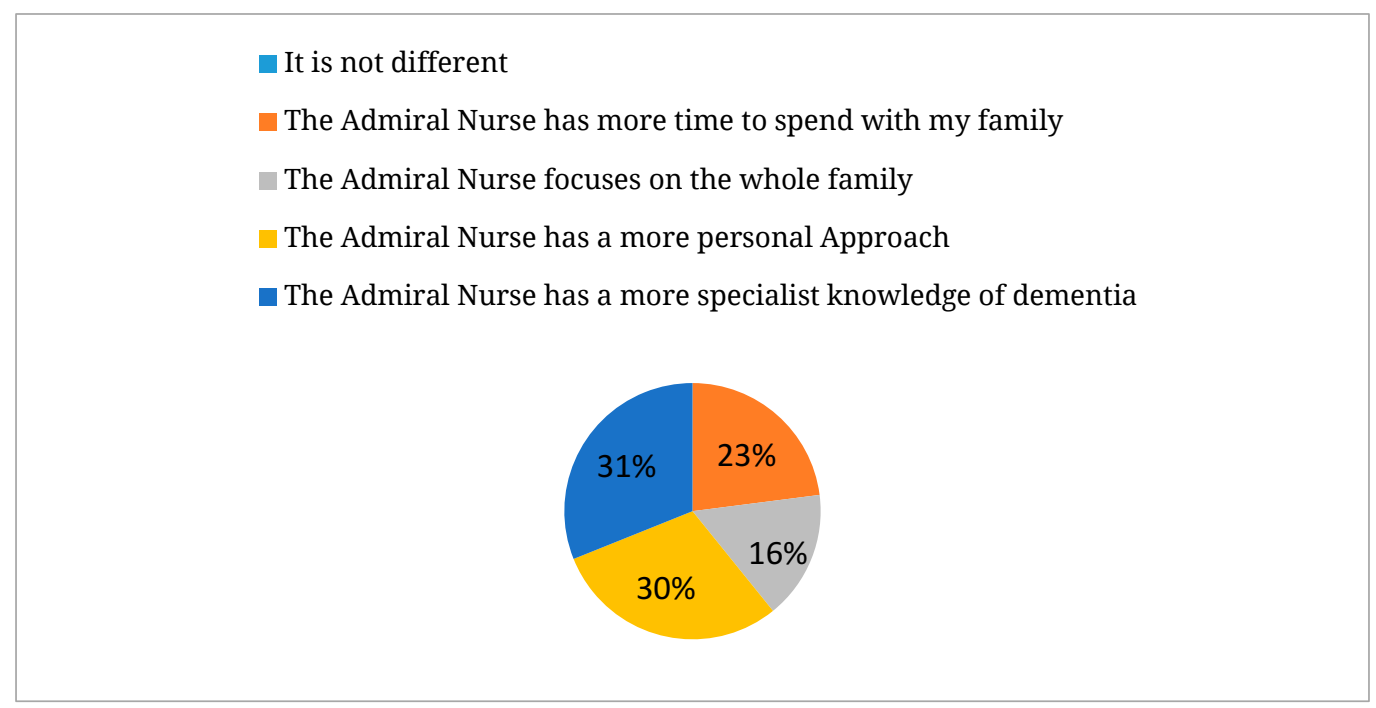

Figure 6. Differentiating between professional roles.

If an Admiral Nurse service had not been available, the majority of respondents (over $70 \% ; n=18$ ) recognised that they would have struggled on by themselves, and half $(n=13,50 \%)$ stated that they would have needed to contact their General Practitioner (GP) (see Figure 7). Respondents were asked to consider any improvements that could be made to the service, but few suggestions were made with the exception of increasing the numbers Admiral Nurse's available.

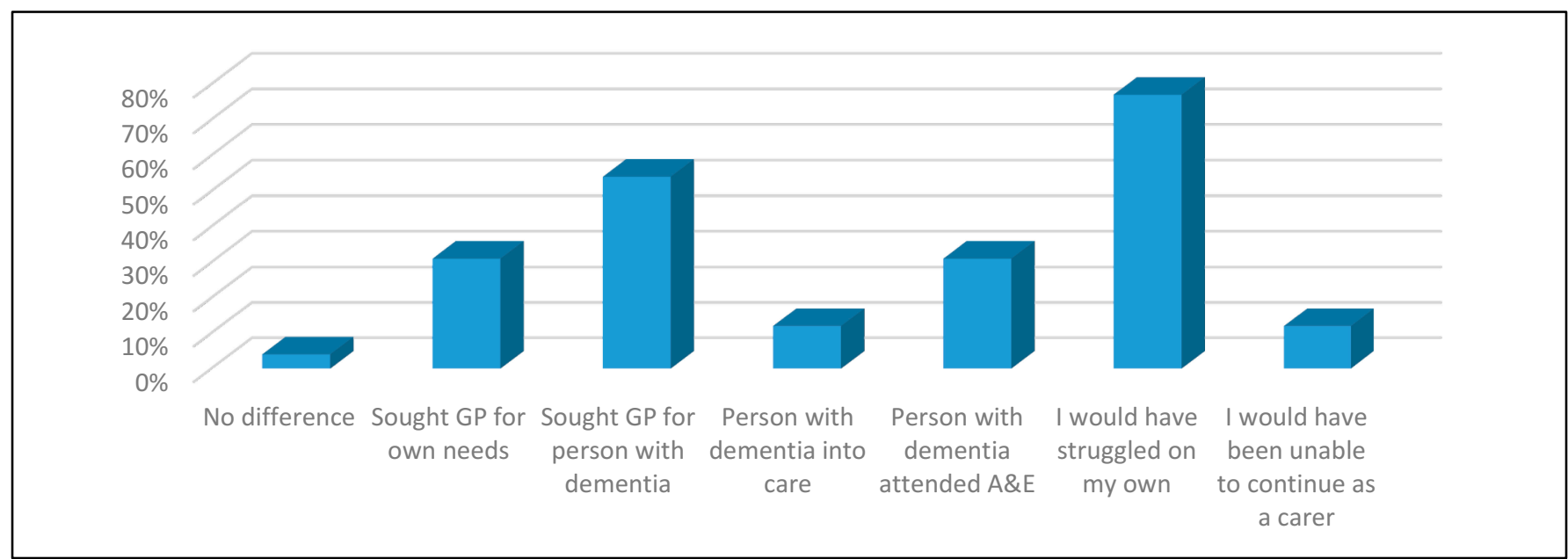

Figure 7. What respondents would do had an Admiral Nurse not been available.

There were also opportunities for participants to add free text in the survey, specifically around how the AN role could be improved and the differences or impact that the AN had made. Following thematic analysis, regarding the latter area (impact), key themes/subthemes included the provision of holistic, meaningful support and the preventative nature of 
this service (see Table 2). Free text in the survey clarified the differences or impact that the Admiral Nurse had made (see Table 2).

Table 2. Key themes around free text suggestions on how the Admiral Nurse service could be improved.

\begin{tabular}{l|l}
\hline Theme & Supporting comments \\
\hline Accessibility & $\begin{array}{l}\text { Increase in admiral nurses “more please” } \\
\text { Should be available to all who need it } \\
\text { Two ANs support for people in their own homes }\end{array}$ \\
\hline Understanding & $\begin{array}{l}\text { Restraints: } \\
\text { Recognition of financial constraints } \\
\text { Unrealistic asking for more admiral nurses }\end{array}$ \\
\hline The service & Excellent service \\
& Very pleased with the service \\
& The AN is so caring, thoughtful and understanding \\
& Spending time \\
\hline
\end{tabular}

The literature well recognises the pressure on carers, and in this evaluation, one respondent recognised their helplessness and desperation around having access to an Admiral Nurse, reflecting: "Without her help, I may well have sunk into depression as a carer...” Knowledge, skills and professional experience were valued and welcomed by respondents as explicit skills of the Admiral Nurse.

Participants also recognised the importance of the AN service, and saw it as a catalyst for change and support. With regards to suggested improvements, overwhelmingly participants identified the need for more ANs, whilst appreciating the inherent financial constraints and challenges associated with this (see Table 3).

Table 3. Free text re the differences that the Admiral Nurse has made.

\begin{tabular}{|c|c|}
\hline Theme & Sub themes \\
\hline Impact & $\begin{array}{l}\text { Holistic, meaningful support: } \\
\text { For others, not just the patient } \\
\text { Practical help and support } \\
\text { "acts in my mum's best interests" } \\
\text { "W is open, honest and incredibly reliable and dependable” } \\
\text { "W. has made a huge difference to me” } \\
\text { "I am now on a carer break to care for my husband full time, getting very little respite. W. is my } \\
\text { window of hope...” } \\
\text { Preventative: } \\
\text { "Without her help, I may well have sunk into depression as a carer...” } \\
\text { "Without W. I honestly believe I would have difficulty coping with the distressing situation I find } \\
\text { myself in. Seeing my mum so severely disabled with dementia is heart-breaking” } \\
\text { "W. has given us some stability, she has been invaluable in giving my mother confidence to } \\
\text { support him” } \\
\text { "I only wish I had had this support earlier in my mums journey with Alzheimer’s" }\end{array}$ \\
\hline
\end{tabular}


Table 3. Cont.

\begin{tabular}{|c|c|}
\hline $\begin{array}{l}\text { Knowledge } \\
\text { and skills }\end{array}$ & $\begin{array}{l}\text { Experience: } \\
\text { "Compassionate and understanding" } \\
\text { Knowledgeable and experienced } \\
\text { "She understands and listens and always makes me feel that I actually can cope" } \\
\text { "For the first time in this long and sometimes lonely journey, we feel supported by someone of } \\
\text { great experience and understanding" } \\
\text { "She keeps me going, always tells me how well we're doing. She never rushes the appointment, } \\
\text { puts up with me being upset, and listens without being judgemental. Offers guidance and } \\
\text { support" } \\
\text { "She is a very special person" }\end{array}$ \\
\hline Coping & $\begin{array}{l}\text { Loneliness, isolation and desperation: } \\
\text { "I was out on my own without any emotional support until I heard about W" } \\
\text { "I no longer felt I was on my own..." } \\
\text { "W. was there to help and support me in the difficult decisions that need to be made on behalf of } \\
\text { someone with Alzheimer's" } \\
\text { "This is invaluable for anyone who finds themselves in this very lonely place" } \\
\text { "W. has become a very important person in our lives" } \\
\text { "Dementia can be a very isolating illness for the patient and their family" } \\
\text { Multiple caring roles: } \\
\text { "I also cared for my father who had cancer...he passed away in December. That combined with } \\
\text { my mum's cancer and dementia, I often felt I was sinking..." } \\
\text { "My father is } 85 \text { with mixed dementia...he lives with my mother who is } 87 \text {. I live } 5 \text { miles away } \\
\text { and am his main carer..." }\end{array}$ \\
\hline The service & $\begin{array}{l}\text { Meaningful: } \\
\text { "Well done to all who provide this service" } \\
\text { Provides practical advise and support } \\
\text { Can be a catalyst for support: contacting GPs etc. } \\
\text { "W. has made the world of difference to us..." } \\
\text { "I honestly do not know if we would cope without her..." }\end{array}$ \\
\hline
\end{tabular}

\section{DISCUSSION}

The nature of families and their geographical and demographic spread (and ergo family support options) has changed considerable over recent years. Many children now grow up with different (and often multiple) parents; as economic fluctuations unfold, they impact upon employment opportunities and finances highlighting the need for flexibility in working patterns. Subsequently, the nature and shape of the family is constantly evolving, as is the impact on society and the role that families play [23]. The burden of the role when caring for a family member with dementia is notably variable, but inevitably broad in accordance to individual needs, and often lonely, unless they have the support they need to help them, as described by a wife carer: 
"I no longer felt I was on my own...invaluable for anyone who finds themselves in this."

—Survey Respondent: Wife as carer

Whilst carers endeavour to do their best when supporting their loved ones, and indeed want to support them as much as they are able, sometimes the complex nature of this deteriorating condition can be extremely demanding, and support for the family and main carers is crucial. Should the inevitable happen and families feel that they can no longer cope, the financial cost of replacing this informal support with formal paid professional health care support is potentially huge, regardless of where the care is delivered. This is an important feature around the impact of the Admiral Nurse role, highlighting the cost effective benefits to the investment of roles of this type for not only the patient, but the whole family.

The support provided was recognised as being person centred, and the four notable areas of support included knowledge and information; holistic assessment; supporting carers with decision making; and helping to anticipate prevent and avert crisis. Combine these with the recognised explicit interventions or skills of the Admiral Nurse (namely spending time and not rushing; listening; responding to questions; and showing compassion, respect and understanding). These highlight a professional who holds the seamless performance of a skilled, knowledgeable doer or expert, as recognised by the Department of Health [24] who see dementia specialists as having "an expert level of skill and knowledge...as dementia champions". The value of this is identified below by one participant:

"The Admiral Nurse is the most valuable, helpful and reliable service that I have been able to access."

—Survey Respondent: Daughter as carer

If the Admiral Nurse service had not been available, it is worrying that $50 \%(n=13)$ of participants would have been reluctant to contact their GP's. This makes one wonder where personal carers are accessing support with their care at the moment; who is providing the acknowledged skills, valued expertise and level of knowledge when the Admiral Nurses (or equivalents) are not so freely available?

The Admiral Nurse in this instance was attached to a dynamic hospice, and the role well embraced as part of its strategic and operational developments. It demonstrates how one hospice constructively changed its thinking regarding their patient population, which historically has focused on malignant diseases, but in recent years has begun to shift in its perspectives. Perhaps the evidence base will inform the modern hospice movement and its patient populations and focus on the wider populations and disease pathways. 


\section{CONCLUSION AND RECOMMENDATIONS}

"The Admiral Nurse is my window of hope...she listens without being non-judgemental...I honestly don't know how I would cope without her."

—Survey Respondent: Wife as carer

Although only a small survey ( $n=26$ ), the outcomes of this evaluation well illustrate the breadth of interventions used by the Admiral Nurse, and the impact this role has on the person with dementia and those family members caring for them. Caring is a somewhat lonely, but rewarding business, and this survey paints an interesting and powerful demographic and "lived experience" picture of this marginalised, somewhat hidden population and their overwhelming appreciation of the service provided by the Admiral Nurse.

As the numbers of people with dementia continue to grow, developing appropriate care and support options remain crucial in supporting individuals and families along this journey. Professionals will have to think creatively, and work proactively and collaboratively, to ensure such services are indeed "fit for purpose". The Admiral Nurse model may be an important development along the dementia continuum of care.

\section{Recommendations}

Expanding hospice services to proactively include patients with dementia seems a natural and logical development since it provides a meaningful and accessible service to an ever increasing population where support is currently inconsistent. It can feasibly address the needs of the four distinct categories of populations potentially involved, namely those who have been dementia care givers, those who are going to be dementia care givers; those who are receiving dementia care and those who will need dementia care. However it is recognised that not all hospices would (or indeed could or should) undertake this strategic development, since the risks associated with financial support alone can be high.

On-going funding for hospice care remains challenging. Patients diagnosed with dementia are increasing, the care and support required has to be funded from somewhere, and if hospices are willing to embrace this population then realistic funding agreements should be achievable and indeed a priority.

This evaluation survey has captured rich data around the holistic impact that an Admiral Nurse can have on the patients and families. More empirical research is required to explore the longer term impact of such support from a strategic, financial, personal, social and logistic perspective, in order to address the ebb and flow of dementia support. 


\section{AUTHOR CONTRIBUTIONS}

Individual authors contributions were: $\mathrm{KD}$ provided the established survey questionnaire from Dementia UK.; SR, CR \& JG designed the study and formatted the questionnaire; SR, CR \& JG analyzed the data; SR \& KD wrote the paper with contributions from CR and JG.

\section{CONFLICTS OF INTEREST}

The authors declare that they have no conflicts of interest.

\section{FUNDING}

The Admiral Nurse project evaluation was supported with funding from Dementia UK and the hospice itself. There was no explicit funding for the development of this article, which was one element of the evaluation.

\section{ACKNOWLEDGEMENTS}

The authors would like to thank a number of people and organisations who have contributed to this this article in so many different ways.

Thank you to the participants who completed the survey, finding time in the busy lives to help professionals to understand their rich, lived experiences. To Dementia Care UK who provided the funding to support the Admiral Nurse project; to the Douglas Macmillan Hospice, who invited us into their "world" to critically explore this project. To all members of the Steering Group who gave their time, expertise and knowledge so freely; and to the Admiral Nurse, who continues to grow from strength to strength in developing their expertise and wisdom.

\section{REFERENCES}

1. World Health Organisation. The ICD-10 Classification of Mental and Behavioural Disorders: Clinical Descriptions and Diagnostic Guidelines. Geneva (Switzerland): WHO; 1992.

2. Sandilyan MB, Dening T. Chapter 1: What is Dementia? In: Harrison Dening K, editor. Evidence-Based Practice in Dementia for Nurses and Nursing Students. 2019. London (UK): Jessica Kingsley Publishers; 2019.

3. Alzheimer's Research. Dementia in the family, the impact on carers. Available from: $\quad$ https://www.alzheimersresearchuk.org/about-us/our-influence/ reports/carers-report/. Accessed 2019 Jun 4.

4. Middleton-Green L, Chatterjee J, Russell S, Downs M. End of life care for people with dementia: A person centred approach. London (UK): Jessica Kingsley Publishers; 2017.

5. Costello J. Adult palliative care for nursing, health and social care. London (UK): Sage Publishing; 2019.

6. Prince M, Knapp M, Guerchet M, McCrone P, Prina M, Comas-Herrera A, et al. Dementia UK: Update. Alzheimer's Society; 2014. Available from: 
https://www.alzheimers.org.uk/site/scripts/download info.php?fileID=2323.

Accessed 2019 Jun 4.

7. Parkin E, Baker C. Briefing Paper Number 07007, Dementia-An overview of policy and services, and statistics on prevalence. London (UK): House of Commons Library; 2015.

8. Newbronner L, Chamberlain R, Borthwick R, Baxter M, Glendinning C. A Road Less Rocky: Supporting carers of people with dementia. London (UK): Carers Trust; 2013.

9. Xie J, Brayne C, Matthews FE. Survival times in people with dementia: analysis from population based cohort study with 14 year follow-up. BMJ. 2008;336(7638):258-62.

10. Sampson EL, Harrison Dening K. Palliative care and end of life care. In: Dening T, Thomas A, editors. Oxford Textbook of Old Age Psychiatry. 2nd ed. Oxford (UK): Oxford University Press; 2013.

11. World Health Organisation. WHO Definition of Palliative Care. Available from: http://www.who.int/cancer/palliative/definition/en/. Accessed 2019 Jun 4.

12. Office for National Statistics. Deaths registered in England and Wales. Available from: https://www.ons.gov.uk/peoplepopulationandcommunity/ birthsdeathsandmarriages/deaths/bulletins/deathsregisteredinenglandandw alesseriesdr/2015. Accessed 2019 Nov 17.

13. Davies E, Higginson IJ. Better Palliative Care for Older People: Report. Copenhagen (Denmark): World Health Organization Europe; 2004.

14. Harrison Dening K, Crowther J, Tolman S. Admiral Nursing: Combining specialist dementia and hospice care. Nurs Palliat Care. 2017;2(3). doi: 10.15761/NPC.1000151

15. Rahman S, Harrison Dening K. The need for specialist nurses in dementia care. Nurs Times. 2016;112(16):14-7.

16. Hospice UK. Hospice enabled dementia care: The first steps. Available from: https://www.hospiceuk.org/docs/default-source/What-We-Offer/Care-

Support-Programmes/dementia-network/hospice-enabled-dementia-care--the-first-steps.pdf?sfvrsn=0. Accessed 2019 Nov 17.

17. Harrison Dening K, Aldridge Z. Admiral Nurse Case management: A model of caregiver support for families affected by dementia. OBM Geriatrics. 2019;3(2). doi: 10.21926/obm.geriatr.1902053

18. Lincoln YS, Guba EG. Research evaluation and policy analysis: Heuristics for disciplined enquiry. Policy Stud Rev. 1986;16:583-9.

19. Clarke A. Evaluation research: An introduction to principles, methods and practice. London (UK): Sage Publishing; 1999.

20. Simmons R. Questionnaires. In: Gilbert N, editor. Researching Social Life. 2nd ed. London (UK): Sage Publishing; 2001.

21. Maio L, Botsford J, Iliffe S. Family carers' experiences of the Admiral Nursing Service: a quantitative analysis of carer feedback. Aging Ment Health. 2016;20(7):669-75.

22. Maio L, Botsford J, Harrison Dening K, Iliffe S. A qualitative analysis: Carer feedback on the Admiral Nurse Services, family-centred dementia support. Aging Ment Health. 2015;20(7):669-75. doi: 10.1080/13607863.2015.1052776 
23. Jenkins S, Perieira I, Evans N. Families in Britain: The impact of changing family structures and what the public think. London (UK): IPSOS Mori; 2007.

24. Department of Health. Making a difference in Dementia: Nursing Vision and Strategy. Available from: https://assets.publishing.service.gov.uk/ government/uploads/system/uploads/attachment data/file/554296/Dementia nursing strategy.pdf. Accessed 2019 Nov 21.

How to cite this article:

Read S, Reeves C, Green J, Harrison Dening K. The Admiral Nurse Role in UK Hospice Care: A Satisfaction Survey Evaluation to Explore Carer Experiences. Adv Geriatr Med Res. 2020;2(1):e200001. 